\title{
An Effective Microwave-Assisted Synthesis of MOF235 with Excellent Adsorption of Acid Chrome Blue K
}

\author{
Jinlong Ge $\mathbb{D}^{1,2}$ Zhong $W u{ }^{1,2}$ Xiaochen Huang, ${ }^{1,2}$ and Ming Ding $\mathbb{D}^{2,3}$ \\ ${ }^{1}$ School of Material and Chemistry Engineering, Bengbu University, Bengbu 233030, China \\ ${ }^{2}$ Engineering Technology Research Center of Si-Based Material, Anhui Province, Bengbu 233030, China \\ ${ }^{3}$ Engineering Laboratory of Si-Based Material, Anhui Province, Bengbu 233030, China
}

Correspondence should be addressed to Jinlong Ge; jinlongge2005@126.com

Received 18 July 2019; Accepted 5 September 2019; Published 29 October 2019

Guest Editor: Fei Ke

Copyright (c) 2019 Jinlong Ge et al. This is an open access article distributed under the Creative Commons Attribution License, which permits unrestricted use, distribution, and reproduction in any medium, provided the original work is properly cited.

An efficient, rapid, and fast kinetics of the metal-organic framework MOF235 was successfully prepared by microwave-assisted thermolysis strategy. Fourier transform infrared spectra (FTIR), X-ray diffraction (XRD), X-ray photoelectron spectroscopy (XPS), $\mathrm{N}_{2}$ adsorption-desorption isotherm, and scanning electron microscopy (SEM) were used to characterize the samples. Experimental results revealed the suitability of MOF235 for use as an adsorbent for acid chrome blue K. The maximum adsorption capacity of acid chrome blue K onto MOF235 can reach to $591.79 \mathrm{mg} \mathrm{g}^{-1}$ at $293 \mathrm{~K}$. The sorption behavior fitted to the pseudo-second-order kinetic model and the Langmuir isotherm. Adsorption of acid chrome blue $\mathrm{K}$ is a spontaneous and endothermic process. Therefore, the as-prepared MOF235 displays a great potential for environmental purification.

\section{Introduction}

Organic dyes are typical pollutants found in many important industries and receive major worldwide concern. Dyes are main organic pollutants because they are toxic or carcinogenic to mammals and other living organisms even at low concentrations [1]. Efficient removal of organic dyes from wastewater has become a severe problem due to its ecological, biological, and environmental importance [2]. Acid chrome blue $\mathrm{K}$ is an azo dye and has been used as a spectrophotometric and electrochemical reagent for protein assay [3].

Dye effluent is usually treated by conventional methods such as adsorption, coagulation, electrochemical degradation, and photocatalysis. Adsorption is considered as one of the simplest, highly effective, and economically beneficial methods to remove the dye [4]. Effective removal of these dyes from aqueous solution is gaining more and more interests [5].

Traditional adsorbent materials, such as clay minerals, activated carbon (AC), carbonaceous materials, ordered mesoporous carbon, carbon nanotubes, and graphene oxides (GO), have been widely applied in the adsorption of organic dyes. However, these adsorbent materials generally have several disadvantages in dye adsorption including small pore sizes or pore volumes and low adsorption capacity [6]. Therefore, the development of advanced porous materials for more effective and inexpensive adsorption is highly valuable [7]

In parallel to the conventional porous materials, much research effort has been devoted to find new adsorbent. Metal-organic frameworks (MOFs) show many interesting characteristic features such as a large specific surface area, low framework density, versatile functionality, controlled porosity, and tailorable structure [8]. These excellent properties have attracted increasing attention for adsorption [9], catalysis, storage, and electrochemistry in recent years [10].

The MOF235 is orange hexagonal single crystals. The crystal structure of the MOF235 is built up from corner sharing octahedral iron trimers. Linear terephthalic acid is connected, and each iron atom is trivalent. MOF235 synthesized by a solvothermal method has been investigated, and it performs high capacity to adsorb $\mathrm{CH}_{4}$ due to the high pore volume and large number of open metal sites [11].

Microwave-assisted synthesis has been widely revealed distinct advantages as an alternative method for the chemical synthesis of organic and inorganic materials [12]. Microwave irradiation has attracted much attention. It has the 
advantages of short reaction time, high reaction rate, and conservation energy.

It has been demonstrated that the microwave-assisted synthesis was one of the most efficient routes to carry out many reactions [13]. Microwave irradiation can accelerate the crystallization of porous materials that require several days or several hours compared with the conventional solvothermal synthesis [14]. A great diversity of MOFs has been prepared quickly and in high yield by a microwave-assisted routes, such as MOF-5, MIL-88B, MIL-53, and UiO-66. The microwave irradiation power, irradiation time, concentration of the reagents, and solvent system were deeply investigated [15]. Microwave heating have a beneficial effect on the properties and performance of materials [16].

In this work, orange octahedral crystals of MOF235 were successfully prepared by a facile and green synthetic route under microwave heating. Moreover, the adsorption capacity for acid chrome blue $\mathrm{K}$ with MOF-235 is about $591.9 \mathrm{mg} \mathrm{g}^{-1}$. The textural and chemical properties of the MOF235 were reported. The adsorption kinetics and mechanism were investigated using the adsorption isotherm technique. The effectiveness of the MOF235 in the adsorption was evaluated. This work provided a fast preparation method for MOF235 and development of a highly successful and efficient adsorbent in acid chrome blue $\mathrm{K}$ wastewater treatment.

\section{Materials and Methods}

2.1. Materials. Ferric chloride hexahydrate $\left(\mathrm{FeCl}_{3}\right)$, terephthalic acid (Sigma-Aldrich, >99\%), N,N-dimethylformamide (DMF), and absolute ethanol were purchased from Shanghai Chemical Reagent Inc. of the Chinese Medicine Group. All reagents were used as received.

2.2. Synthesis of MOF235. In a typical synthesis, a mixture of $0.3015 \mathrm{~g}$ terephthalic acid was dissolved in $30 \mathrm{~mL}$ DMF solvent and the mixture was stirred for $10 \mathrm{~min}$. Then, $0.3000 \mathrm{~g}$ of $\mathrm{FeCl}_{3} \cdot 6 \mathrm{H}_{2} \mathrm{O}$ was added into the solution and stirred for $10 \mathrm{~min}$; the reactant mixture of $30 \mathrm{~mL}$ and $30 \mathrm{~mL}$ of ethanol was dispersed into the round Pyrex flask [11]. The round flask was put into ultrasonic and microwave-assisted extraction (Shanghai CW-2000) and irradiated simultaneously by microwaves under the protection of nitrogen for a specified period. After cooling down to room temperature, the orange resultant solid was collected by centrifugation, washed with DMF-ethanol $(1: 1, v / v)$ mixture and finally dried in a vacuum at $423 \mathrm{~K}$ for $12 \mathrm{~h}$ and the orange octahedral crystals of MOF235 were obtained.

2.3. Adsorption Test. In a typical preparation process, $10 \mathrm{mg}$ of MOF235 was added to a solution with $50 \mathrm{~mL}$ of acid chrome blue $\mathrm{K}$ at initial concentration from $40 \mathrm{ppm}$ to $140 \mathrm{ppm}$. The solution was shaked under mechanical conditions for different times. The residual concentration of the dyes was determined at the maximum wavelength using UV-vis spectroscopy. The adsorption capacities were calculated using the calibration curve.

2.4. Characterizations. The synthesized MOF235 were thoroughly characterized by various sophisticated analytical tech-

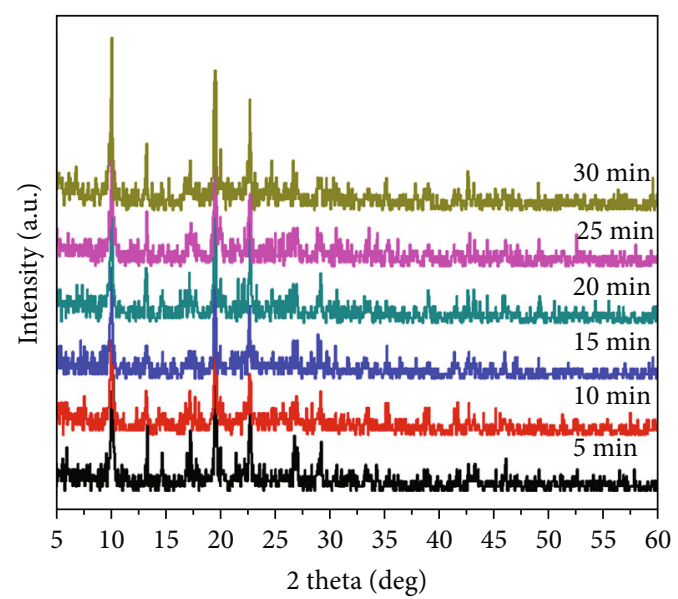

FIgURE 1: XRD patterns of the as-synthesized MOF235 with different microwave times.

niques. X-ray diffraction (XRD) experiments were conducted using an X-ray diffractometer with the $\mathrm{Cu}$ target (SmartLab) operating at $36 \mathrm{kV}$ and $25 \mathrm{~mA}$ from 5 to $70^{\circ}$. Fourier transform infrared (FTIR) spectra of powder samples were obtained in the $400-4000 \mathrm{~cm}^{-1}$ range with a resolution of $4 \mathrm{~cm}^{-1}$ using a Nicolet Nexus 870 FTIR spectrometer. X-ray photoelectron spectroscopy (XPS) analysis was carried out in the Thermo Scientific K-Alpha spectrometer using monochromated $\mathrm{Al} \mathrm{Ka} \mathrm{X-rays.} \mathrm{Ultraviolet} \mathrm{absorbance} \mathrm{spectra} \mathrm{were}$ collected on a Shimadzu UV 3600 plus spectrophotometer over a range of $200-800 \mathrm{~nm}$. Nitrogen adsorptiondesorption isotherms were measured at $77 \mathrm{~K}$ by multipoint BET and a Barrett-Joyner-Halenda (BJH) method using a Micromeritics ASAP 3020 analyzer. The samples were heated at $150^{\circ} \mathrm{C}$ for $12 \mathrm{~h}$ prior to each test. The morphology and microstructure were observed by a field emission scanning electron microscope (SEM: Hitachi S-4800). Thermogravimetric analysis was determined from room temperature to $800^{\circ} \mathrm{C}$ with a heating rate of $10^{\circ} \mathrm{C} / \mathrm{min}$ using a Pyris 1 TGA-1.

\section{Results and Discussion}

3.1. Characterization of MOF235. The crystalline nanostructures and phase purities of the MOF235 samples were recorded with X-ray distraction (XRD) in Figure 1. Strong major peaks of the samples were observed at $2 \theta=9.7^{\circ}$, $10.8^{\circ}, 12.6^{\circ}, 19.0^{\circ}, 22.0^{\circ}$, and $26^{\circ}$, which are in good consistent with the previously reported literature [17]. In the XRD patterns, the minimum microwave time to obtain complete crystallinity MOF235 was required for $15 \mathrm{~min}$. The sharp crystalline of the reflections derived from the MOF235 increases with the prolonged reaction time under microwave. This indicated that the well crystallinity of MOF235 in the samples is proportional to the reaction time about $20 \mathrm{~min}$ $[18,19]$. The results described the advantages of the effective and convenient microwave-assisted method. The intensities of all crystallinity peaks which increased gradually in short periods could be attributed to the fast heating precursor and avoid thermal gradients $[20,21]$. It also demonstrated that the increased irradiation time leads to high yields and 


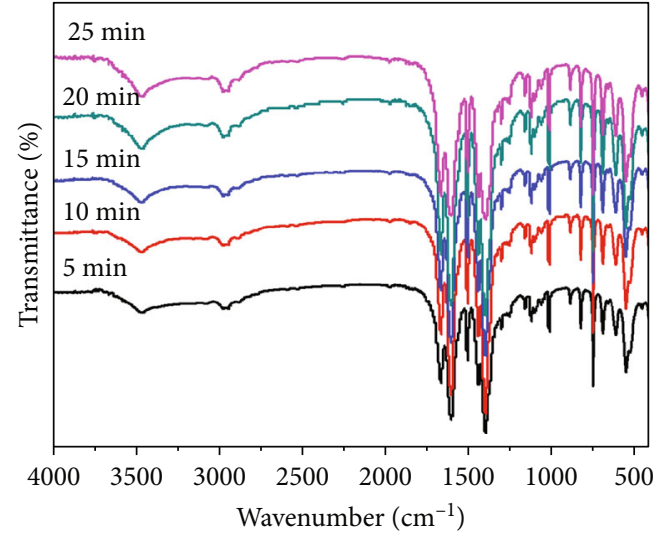

FIGURE 2: FTIR of the as-synthesized MOF235 with different microwave irradiation times.

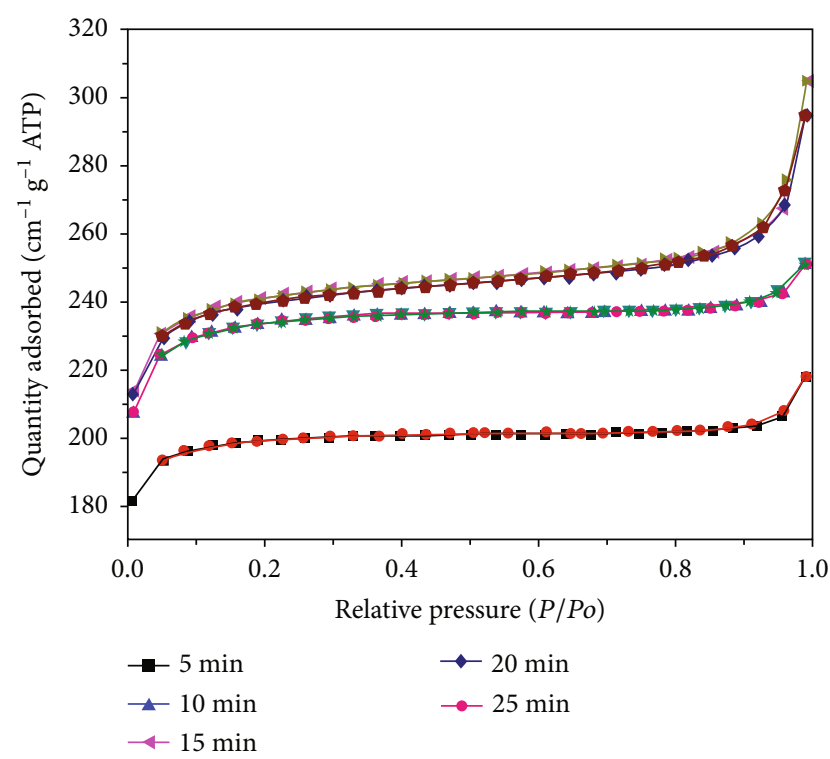

FIgURE 3: Nitrogen adsorption-desorption isotherms of the MOF235.

larger crystals [22]. It indicated that microwave heating was more effective than the convenient heating.

Fourier transform infrared (FTIR) spectra of the MOF235 were shown in Figure 2. All of the samples display similar spectra in general. The main spectra peaks of MOF235 were at $3440 \mathrm{~cm}^{-1}, 2931 \mathrm{~cm}^{-1}, \quad 1597 \mathrm{~cm}^{-1}$, $1398 \mathrm{~cm}^{-1}, 1016 \mathrm{~cm}^{-1}, 810 \mathrm{~cm}^{-1}, 748 \mathrm{~cm}^{-1}$, respectively. The peaks observed at $1597 \mathrm{~cm}^{-1}$ were attributed to the asymmetric C-O bonds. The peaks at $1398 \mathrm{~cm}^{-1}$ were attributed to symmetric stretch vibrations in the carboxyl groups. According to the lower frequencies, the bands around $810 \mathrm{~cm}^{-1}$, $748 \mathrm{~cm}^{-1}$, and $710 \mathrm{~cm}^{-1}$ were attributed to the mixture with the $\mathrm{C}-\mathrm{H}$ vibration, $\mathrm{C}=\mathrm{C}$ stretch, $\mathrm{OH}$ bend, and $\mathrm{O}-\mathrm{C}-\mathrm{O}$ bend in $\mathrm{H}_{2} \mathrm{BDC}$ [23].

Nitrogen adsorption isotherms of the samples prepared under different preparation conditions are shown in Figure 3. All samples confirmed a type I sorption isotherm, indicating a typical microporous structure. The results

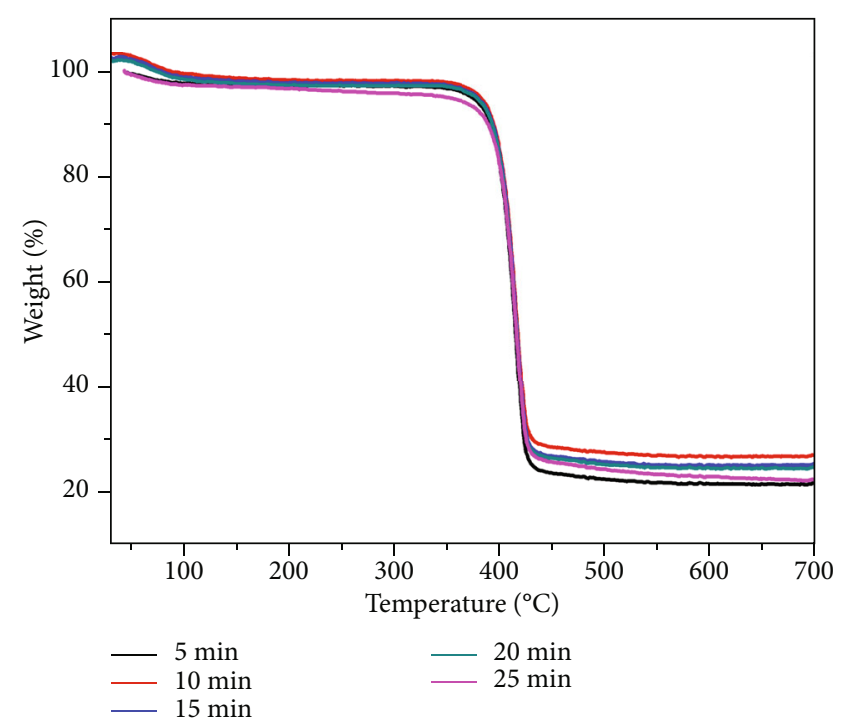

FIgURE 4: TG of the as-synthesized MOF235.

revealed that the BET surface area was significantly increased from $444.25,583.20,602.72,620.53$, and $729.21 \mathrm{~m}^{2} \mathrm{~g}^{-1}$ of the samples by microwave heating time. It proves that the microwave-assisted preparation of MOF235 is feasible and efficient. The pore size distribution is an important influence factor of an adsorbent. It will have a great impact on the size and shape of a given dye molecules. The average pore size of MOF235 is $4.13 \mathrm{~nm}$. When the adsorbent pore diameter is as large as 1.7 times that of the adsorbate, adsorption can reach to the most effective results [24]. However, the amount of micropores decreased significantly after the incorporation. The increase in the BET surface area and micropore volume of the MOF235 could be attributed to the loss of the wellordered structure; the pore can be an efficient space for large substrates which allows the dye to go inside the pore and react with MOF235.

The thermal stability of MOF235 was carried out by TGA to investigate the material stability and the correlation between the reaction time and the structural integrity. As shown in Figure 4(a), the TGA curves of all the samples exhibit a degradation at the temperature of $400^{\circ} \mathrm{C}$. The weight loss of the samples MOF235 showed similar thermal curves. The maximum structural integrity and robustness of the MOF235 were achieved with a microwave irradiation time of $25 \mathrm{~min}$. Moreover, the thermal stabilities of these MOF235 were consistent with those obtained using the previously reported solvothermal approach [25]. With the extended response time from 5 to $10 \mathrm{~min}$, the sample crystals were still underdeveloped and with some unreacted precursors attached in the pore. The full growth of crystals was completed after $15 \mathrm{~min}$. The TGA curve results showed that the MOF235 have high thermal stability in the adsorption dye reaction [26].

$\mathrm{X}$-ray photoelectron spectral (XPS) analyses were applied to analyze the elemental distribution, surface composition, and bond of the samples and their valence states [27]. It shows that the sample surface consists of carbon, nitrogen, 


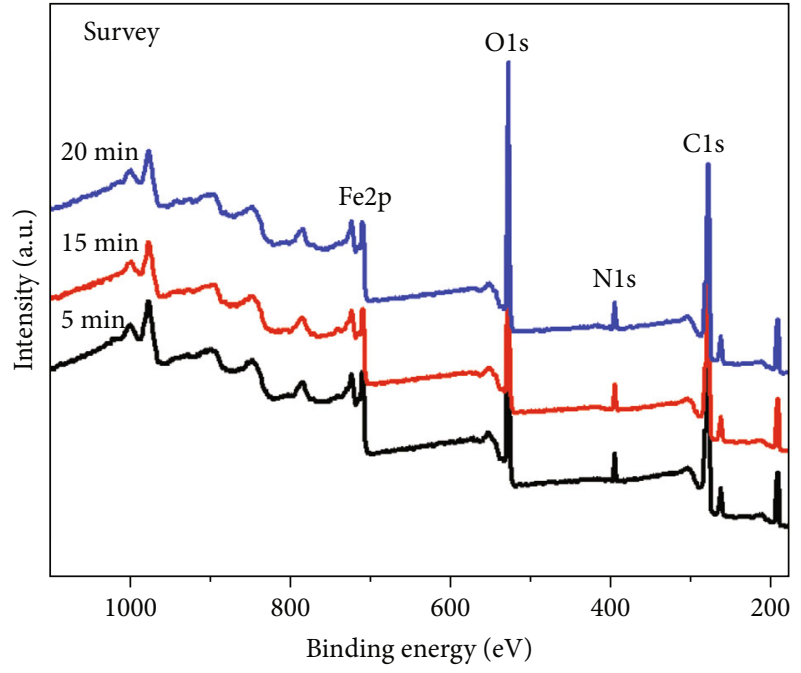

(a)

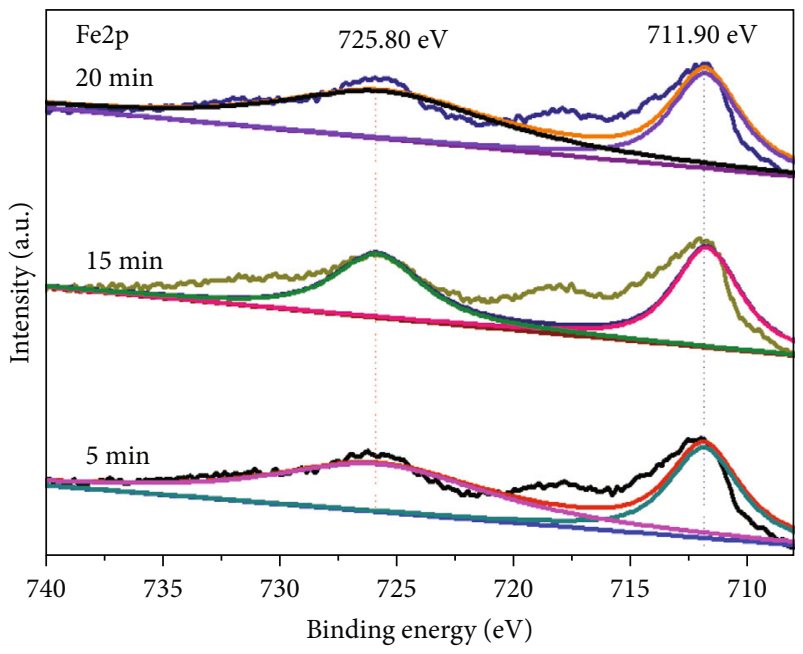

(c)

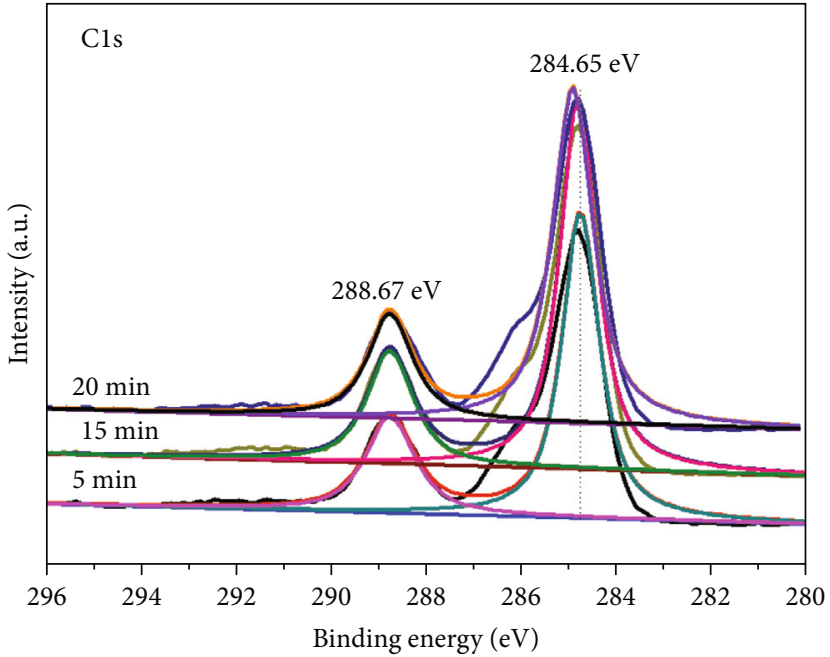

(b)

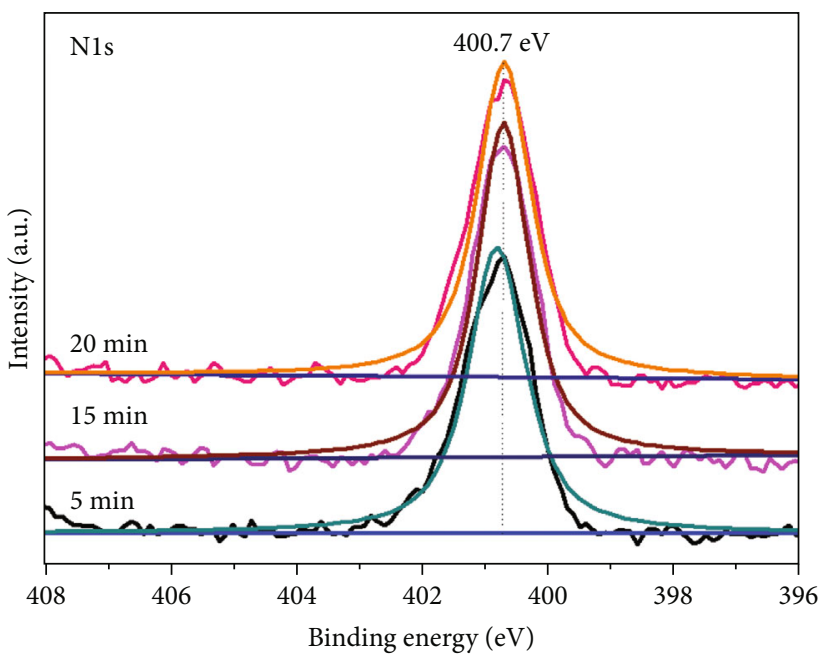

(d)

FIGURE 5: XPS spectra of MOF235: (a) survey, (b) C1s, (c) Fe2p, and (d) N1s.

oxygen, and iron, with binding energies of $\mathrm{C} 1 \mathrm{~s}, \mathrm{~N} 1 \mathrm{~s}, \mathrm{O} 1 \mathrm{~s}$, and Fe2p, respectively (Figure 5(a)). As shown in Figure 5(b), the fitting result of the C1s spectrum of MOF235 suggests the existence of two peak components of $\mathrm{C}=\mathrm{C}$ and $\mathrm{C}-\mathrm{C}$ $(284.65 \mathrm{eV})$ and $\mathrm{O}-\mathrm{C}=\mathrm{O}(288.67 \mathrm{eV})$, indicated that there were two types of chemical environments for carbon in the samples [28]. The two characteristic peaks at 711.90 and $725.80 \mathrm{eV}$ (Fe2p region) indicated the presence of $\mathrm{Fe}^{3+}$ species (Figure 5(c)). The peak centered at $400.7 \mathrm{eV}$ can be assigned to graphitic $\mathrm{N}$, in agreement with the $\mathrm{N}$ states in N/C (Figure 5(d)), indicating the change of chemical environment of nitrogen in MOF235.

The MOF235 morphology of the microwave heating method under different times was studied by SEM in Figure 6. The well-crystallized octahedral morphological materials are built up from corner-sharing octahedral iron trimers that are connected through terephthalic acid linear links. The $\mathrm{Fe}_{3} \mathrm{O}$ plane of each trimer has $\mathrm{Fe}-(\mu 3-\mathrm{O})$ - $\mathrm{Fe}$ angles $\left(120^{\circ}\right)$ and the two adjacent Fe ion separation of $3.33 \AA$ [17]. The octahedral crystallites have the particle size around
$450 \mathrm{~nm}$ and a uniform size distribution. The SEM images show that the materials have an obvious advantage of a higher degree of crystallinity with the extension of microwave irradiation time.

3.2. Adsorption Properties of Acid Chrome Blue $K$ on MOF235. Adsorption equilibrium of acid chrome blue $\mathrm{K}$ onto MOF235 was studied at six initial concentrations of 40, 60, 80, 100, 120, and $140 \mathrm{ppm}$. As shown in Figure 7, it was clearly shown that the adsorption quantity of acid chrome blue $\mathrm{K}$ increased sharply within $50 \mathrm{~min}$ and no marked changes are observed with further increases in contact time. It is suggested that the samples were allowed reacting for $200 \mathrm{~min}$ to ensure adsorption equilibrium. During the desorption process, the equilibrium adsorption amounts of acid chrome blue $\mathrm{K}$ were 94.81, 189.60, 259.84, 366.05, 464.84 , and $591.79 \mathrm{mg} \mathrm{g}^{-1}$, respectively. The results indicated that the adsorption amounts were improved with the increase of the initial concentrations and it could reach the 


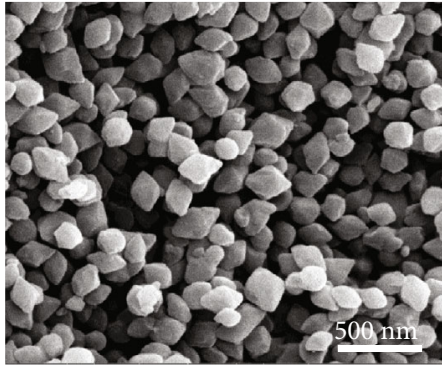

(a)

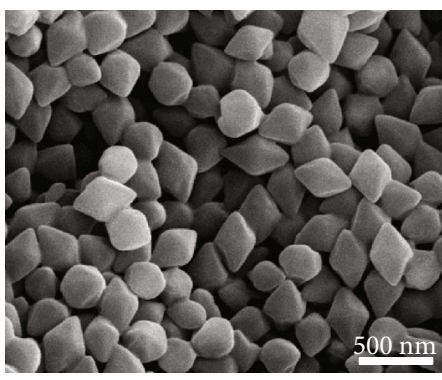

(c)

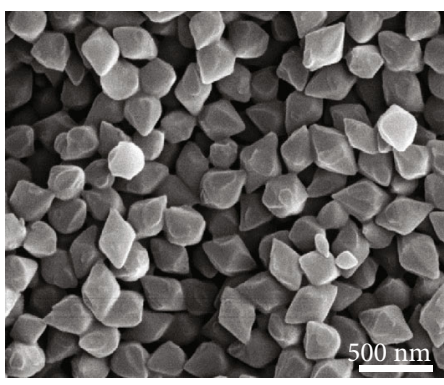

(e)

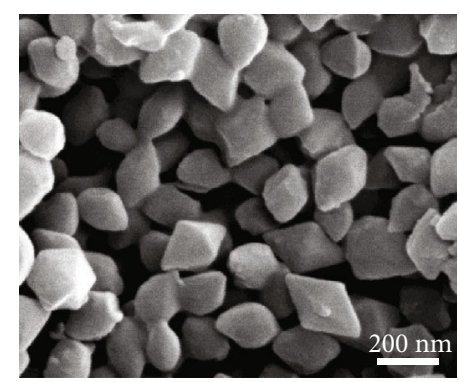

(b)

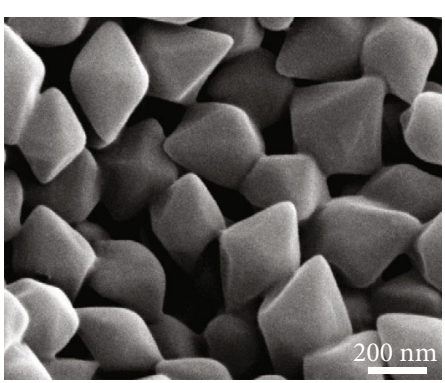

(d)

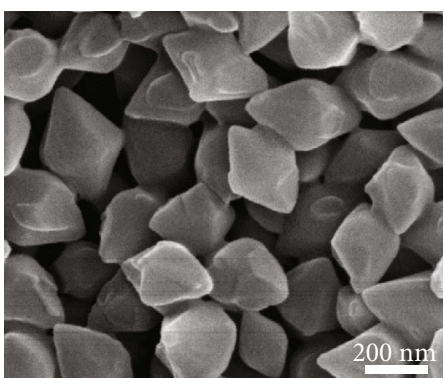

(f)

FIGURE 6: SEM micrographs of MOF235: (a) $10 \mathrm{~min}$, (b) $15 \mathrm{~min}$, and (c) $15 \mathrm{~min}$

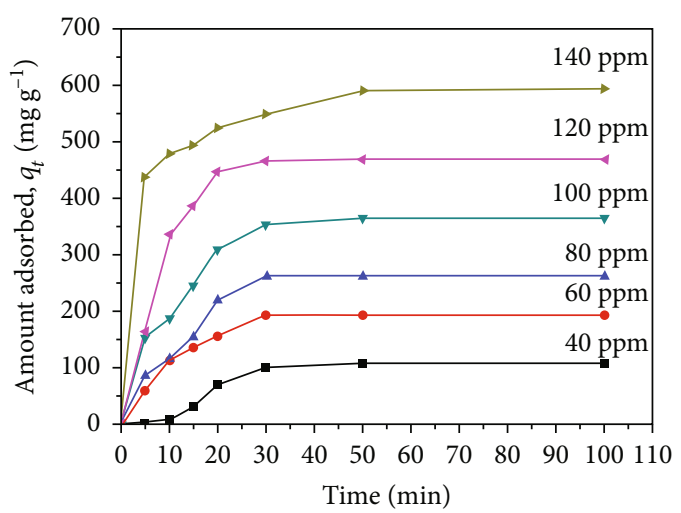

FIgURE 7: Adsorption amounts of acid chrome blue K with different initial concentrations.

maximums of $591.79 \mathrm{mg} \mathrm{g}^{-1}$ from the $140 \mathrm{ppm}$ initial concentration aqueous solution [29].

Adsorption kinetics were investigated to study the mechanism of adsorption which is important for adsorption efficiency of the acid chrome blue $\mathrm{K}$ in aqueous solutions [30]. The pseudo-first-order and pseudo-second-order models were both usually applied to the experimental data [31]. The models are used to explore the potential rate controlling the phenomenon in the adsorption of acid chrome blue $\mathrm{K}$ onto MOF235 [32]. The adsorption rate is proportional to the square of the number of unoccupied adsorption sites, and the rate equation is

$$
\begin{gathered}
\frac{d_{q}}{d_{t}}=k_{2}\left(q_{e}-q\right)^{2}, \\
\frac{t}{q_{t}}=\frac{1}{q_{e}^{2} k_{2}}+\frac{t}{q_{e}},
\end{gathered}
$$

where $q_{e}$ and $q_{t}(\mathrm{mg} / \mathrm{g})$ refer to the amounts of acid chrome blue $\mathrm{K}$ adsorbed at equilibrium and at time $t$, respectively. $k_{2}\left(\mathrm{~g} \mathrm{mg}^{-1} \mathrm{~min}^{-1}\right)$ represents the rate constants [33]. It is obvious that the experimental kinetic data fitted better with the pseudo-second-order rate model. The higher coefficients of $R^{2}$ and lower normalized standard deviation are better than those in the pseudo-first-order kinetic model [34]. As shown in Figure 8, all the coefficients of the pseudo-secondorder model were higher than 0.999 for all the initial acid chrome blue $\mathrm{K}$ concentrations at $293 \mathrm{~K}$. It implied that the 


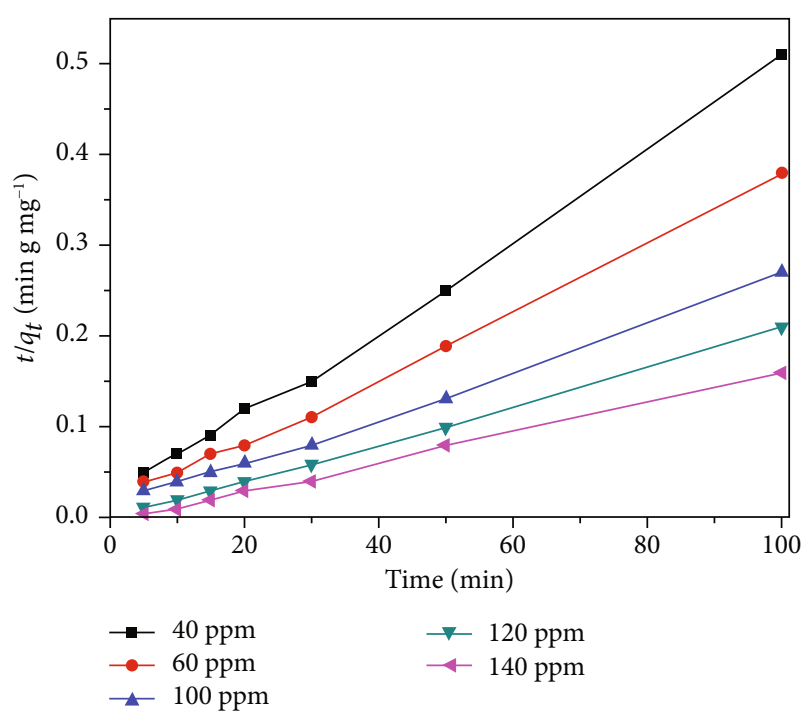

FIgURE 8: Langmuir plots of the isotherms.

adsorption process was a combination of physical and chemical adsorption [35].

The pseudo-first-order kinetics model is a widely used monolayer adsorption model. The equilibrium adsorption data of acid chrome blue K on MOF235 was further evaluated through Langmuir and Freundlich isotherm equations [36, 37]. The Langmuir isotherm is valid for monolayer adsorption onto a surface containing a finite number of identical adsorption sites [29]. The Freundlich isotherm is applied for multilayer adsorption of adsorbates with a heterogeneous surface and a nonuniform distribution of adsorption heat [38]. Their linear forms are as follows:

$$
\frac{C_{e}}{q_{e}}=\frac{C_{e}}{Q_{0}}+\frac{1}{Q_{0} b},
$$

where $q_{e}$ is the amount of adsorbate adsorbed per unit mass of adsorbent $\left(\mathrm{mg} \mathrm{g}^{-1}\right), C_{e}$ is the retained adsorbate concentration at equilibrium $\left(\mathrm{mg} \mathrm{L}^{-1}\right)$ [39], $q_{0}$ is the maximum adsorption capacity, and $b$ is the adsorption energy, obtained from the slope and intercept of the plot of $C_{e} / q_{e}$ against $C_{e}$, respectively [40], and found to be $131.8 \mathrm{mgg}^{-1}$ and $0.0485 \mathrm{~L} \mathrm{mg}^{-1}$ with the correlation of 0.995 .

\section{Conclusions}

In summary, the microwave-assisted thermolysis strategy is simple, rapid, and robust, thereby providing a promising route for the synthesis of MOF235. Acid chrome blue K can be efficiently removed with MOF235. The adsorption kinetics and adsorption isotherms were investigated in detail. All of the MOF235 exhibited high adsorption capacities and fast adsorption kinetics. It is indicated that MOF235 under microwave can be applied in the highly attractive adsorbent for the removal of acid chrome blue $\mathrm{K}$.

\section{Data Availability}

The data used to support the findings of this study are available from the corresponding author upon request.

\section{Conflicts of Interest}

The authors declare that there is no conflict of interests regarding the publication of this paper.

\section{Acknowledgments}

This work was supported by the Major Project Natural Science Fund of Anhui Department of Education (Nos. KJ2019ZD62, KJ2018ZD055, KJ2019A0852, and KJ2019A0848) and Funding of High Research for High Talents (BBXY2018KYQD08 and BBXY2018KYQD16).

\section{References}

[1] S. Cheng, L. Zhang, H. Xia et al., "Adsorption behavior of methylene blue onto waste-derived adsorbent and exhaust gases recycling," RSC Advances, vol. 7, no. 44, pp. 2733127341, 2017.

[2] Y. He, T. Xu, J. Hu et al., "Amine functionalized 3D porous organic polymer as an effective adsorbent for removing organic dyes and solvents," RSC Advances, vol. 7, no. 48, pp. 30500-30505, 2017.

[3] L. Mouni, L. Belkhiri, J. C. Bollinger et al., "Removal of methylene blue from aqueous solutions by adsorption on kaolin: kinetic and equilibrium studies," Applied Clay Science, vol. 153, pp. 38-45, 2018.

[4] C. Li, H. Xia, L. Zhang et al., "Kinetics, thermodynamics, and isotherm study on the removal of methylene blue dye by adsorption via copper modified activated carbon," Research on Chemical Intermediates, vol. 44, no. 4, pp. 2231-2250, 2018.

[5] D. Li, W. Dong, S. Sun, Z. Shi, and S. Feng, "Photocatalytic degradation of acid chrome blue $\mathrm{K}$ with porphyrin-sensitized $\mathrm{TiO}_{2}$ under visible light," The Journal of Physical Chemistry C, vol. 112, no. 38, pp. 14878-14882, 2008.

[6] E. M. Dias and C. Petit, "Towards the use of metal-organic frameworks for water reuse: a review of the recent advances in the field of organic pollutants removal and degradation and the next steps in the field," Journal of Materials Chemistry $A$, vol. 3, no. 45, pp. 22484-22506, 2015.

[7] L. Wen, X. Wang, H. Shi, K. Lv, and C. Wang, "A multifunctional cadmium-organic framework comprising tricarboxytriphenyl amine: selective gas adsorption, liquid-phase separation and luminescence sensing," RSC Advances, vol. 6, no. 2, pp. 1388-1394, 2016.

[8] H. K. Kala, R. Mehta, K. K. Sen, R. Tandey, and V. Mandal, "Strategizing method optimization of microwave-assisted extraction of plant phenolics by developing standard working principles for universal robust optimization," Analytical Methods, vol. 9, no. 13, pp. 2089-2103, 2017.

[9] F. Jeremias, V. Lozan, S. K. Henninger, and C. Janiak, "Programming MOFs for water sorption: amino-functionalized MIL-125 and UiO-66 for heat transformation and heat storage applications," Dalton Transactions, vol. 42, no. 45, pp. $15967-$ 15973, 2013. 
[10] P. Kumar, K. H. Kim, E. E. Kwon, and J. E. Szulejko, "Metalorganic frameworks for the control and management of air quality: advances and future direction," Journal of Materials Chemistry A, vol. 4, no. 2, pp. 345-361, 2016.

[11] Y. Li, G. Hou, J. Yang et al., "Facile synthesis of MOF 235 and its superior photocatalytic capability under visible light irradiation," RSC Advances, vol. 6, no. 20, pp. 16395-16403, 2016.

[12] F. Iskandar, U. Hikmah, E. Stavila, and A. H. Aimon, "Microwave-assisted reduction method under nitrogen atmosphere for synthesis and electrical conductivity improvement of reduced graphene oxide (rGO)," RSC Advances, vol. 7, no. 83, pp. 52391-52397, 2017.

[13] Y. Kalinovskyy, N. J. Cooper, M. J. Main, S. J. Holder, and B. A. Blight, "Microwave-assisted activation and modulator removal in zirconium MOFs for buffer-free CWA hydrolysis," Dalton Transactions, vol. 46, no. 45, pp. 15704-15709, 2017.

[14] A. U. H. S. Rana, M. Kang, and H. S. Kim, "Microwave-assisted facile and ultrafast growth of $\mathrm{ZnO}$ nanostructures and proposition of alternative microwave-assisted methods to address growth stoppage," Scientific Reports, vol. 6, no. 1, article 24870, 2016.

[15] J. He, Y. Zhang, X. Zhang, and Y. Huang, "Highly efficient Fenton and enzyme-mimetic activities of $\mathrm{NH}_{2}-\mathrm{MIL}-88 \mathrm{~B}(\mathrm{Fe})$ metal organic framework for methylene blue degradation," Scientific Reports, vol. 8, no. 1, article 5159, 2018.

[16] B. Reeja-Jayan, K. L. Harrison, K. Yang, C. L. Wang, A. E. Yilmaz, and A. Manthiram, "Microwave-assisted lowtemperature growth of thin films in solution," Scientific Reports, vol. 2, no. 1, article 1003, 2012.

[17] A. C. Sudik, A. P. Côté, and O. M. Yaghi, "Metal-organic frameworks based on trigonal prismatic building blocks and the new "acs" topology," Inorganic Chemistry, vol. 44, no. 9, pp. 2998-3000, 2005.

[18] C. Zhang, H. Zhang, R. Li, and Y. Xing, "Morphology and adsorption properties of chitosan sulfate salt microspheres prepared by a microwave-assisted method," RSC Advances, vol. 7, no. 76, pp. 48189-48198, 2017.

[19] Y. J. Heo and S. J. Park, "Facile synthesis of MgO-modified carbon adsorbents with microwave-assisted methods: effect of $\mathrm{MgO}$ particles and porosities on $\mathrm{CO}_{2}$ capture," Scientific Reports, vol. 7, no. 1, article 5653, 2017.

[20] H. Reinsch and N. Stock, "Synthesis of MOFs: a personal view on rationalisation, application and exploration," Dalton Transactions, vol. 46, no. 26, pp. 8339-8349, 2017.

[21] H. Liu, T. Liu, M. Takafuji, H. Qiu, and H. Ihara, "Monodisperse core shell melamine formaldehyde polymer-modified silica microspheres prepared using a facile microwaveassisted method," New Journal of Chemistry, vol. 41, no. 20, pp. 11517-11520, 2017.

[22] F. H. Wei, D. Chen, Z. Liang, S. Q. Zhao, and Y. Luo, "Synthesis and characterization of metal-organic frameworks fabricated by microwave-assisted ball milling for adsorptive removal of Congo red from aqueous solutions," RSC Advances, vol. 7, no. 73, pp. 46520-46528, 2017.

[23] Y. Han, M. Liu, K. Li et al., "Facile synthesis of morphology and size-controlled zirconium metal-organic framework UiO-66: the role of hydrofluoric acid in crystallization," CrystEngComm, vol. 17, no. 33, pp. 6434-6440, 2015.

[24] M. V. B. Krishna, G. Venkateswarlu, and D. Karunasagar, "Development of a simple and robust microwave assisted decomposition method for the determination of rare earth ele- ments in coal fly ash by ICP-OES," Analytical Methods, vol. 9, no. 13, pp. 2031-2040, 2017.

[25] Y. H. Huang, W. S. Lo, Y. W. Kuo, W. J. Chen, C. H. Lin, and F. K. Shieh, "Green and rapid synthesis of zirconium metalorganic frameworks via mechanochemistry: uio-66 analog nanocrystals obtained in one hundred seconds," Chemical Communications, vol. 53, no. 43, pp. 5818-5821, 2017.

[26] R. Babu, R. Roshan, A. C. Kathalikkattil, D. W. Kim, and D. W. Park, "Rapid, microwave-assisted synthesis of cubic, threedimensional, highly porous MOF-205 for room temperature $\mathrm{CO}_{2}$ fixation via cyclic carbonate synthesis," ACS Applied Materials \& Interfaces, vol. 8, no. 49, pp. 33723-33731, 2016.

[27] M. Anbia, V. Hoseini, and S. Sheykhi, "Sorption of methane, hydrogen and carbon dioxide on metal-organic framework, iron terephthalate (MOF-235)," Journal of Industrial and Engineering Chemistry, vol. 18, no. 3, pp. 1149-1152, 2012.

[28] C. A. Bizzi, M. F. Pedrotti, J. S. Silva, J. S. Barin, J. A. Nóbrega, and E. M. M. Flores, "Microwave-assisted digestion methods: towards greener approaches for plasma-based analytical techniques," Journal of Analytical Atomic Spectrometry, vol. 32, no. 8, pp. 1448-1466, 2017.

[29] E. Haque, J. W. Jun, and S. H. Jhung, “Adsorptive removal of methyl orange and methylene blue from aqueous solution with a metal-organic framework material, iron terephthalate (MOF-235)," Journal of Hazardous Materials, vol. 185, no. 1, pp. 507-511, 2011.

[30] C. Du, Y. Xue, Z. Wu, and Z. Wu, "Microwave-assisted onestep preparation of macadamia nut shell-based activated carbon for efficient adsorption of reactive blue," New Journal of Chemistry, vol. 41, no. 24, pp. 15373-15383, 2017.

[31] J. Klinowski, F. A. Almeida Paz, P. Silva, and J. Rocha, "Microwave-assisted synthesis of metal-organic frameworks," Dalton Transactions, vol. 40, no. 2, pp. 321-330, 2011.

[32] Y. He, M. Pei, N. Xue, L. Wang, and W. Guo, "Synthesis of sodium polyacrylate-bentonite using in situ polymerization for $\mathrm{Pb}^{2+}$ removal from aqueous solutions," RSC Advances, vol. 6, no. 53, pp. 48145-48154, 2016.

[33] M. Taddei, P. V. Dau, S. M. Cohen et al., "Efficient microwave assisted synthesis of metal-organic framework UiO-66: optimization and scale up," Dalton Transactions, vol. 44, no. 31, pp. 14019-14026, 2015.

[34] B. Saha, S. Das, J. Saikia, and G. Das, "Preferential and enhanced adsorption of different dyes on iron oxide nanoparticles: a comparative study," The Journal of Physical Chemistry C, vol. 115, no. 16, pp. 8024-8033, 2011.

[35] S. Deng, G. Zhang, Y. Li, Y. Dou, and P. Wang, "Facile preparation of amidoxime-functionalized fiber by microwaveassisted method for the enhanced adsorption of chromium(VI) from aqueous solution," RSC Advances, vol. 6, no. 69, pp. 64665-64675, 2016.

[36] L. Xu, Y. S. Ding, C. H. Chen et al., "3D flowerlike $\alpha$-nickel hydroxide with enhanced electrochemical activity synthesized by microwave-assisted hydrothermal method," Chemistry of Materials, vol. 20, no. 1, pp. 308-316, 2008.

[37] V. Bon, I. Senkovska, J. D. Evans, M. Wöllner, M. Hölzel, and S. Kaskel, "Insights into the water adsorption mechanism in the chemically stable zirconium-based MOF DUT-67 - a prospective material for adsorption-driven heat transformations," Journal of Materials Chemistry A, vol. 7, no. 20, pp. 1268112690, 2019. 
[38] H. Guo, F. Lin, J. Chen, F. Li, and W. Weng, "Metal-organic framework MIL-125(Ti) for efficient adsorptive removal of rhodamine B from aqueous solution," Applied Organometallic Chemistry, vol. 29, no. 1, pp. 12-19, 2015.

[39] J. M. Yang, R. J. Ying, C. X. Han et al., “Adsorptive removal of organic dyes from aqueous solution by a Zr-based metal organic framework effects of Ce(III) doping," Dalton Transactions, vol. 47, no. 11, pp. 3913-3920, 2018.

[40] P. Yang, W. Wei, and L. Yang, "Simultaneous voltammetric determination of dihydroxybenzene isomers using a poly(acid chrome blue K)/carbon nanotube composite electrode," Microchimica Acta, vol. 157, no. 3-4, pp. 229-235, 2007. 


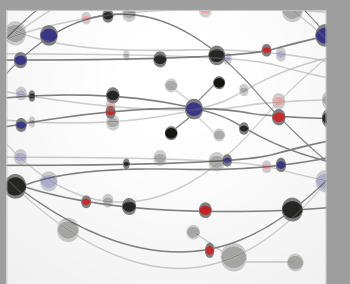

The Scientific World Journal
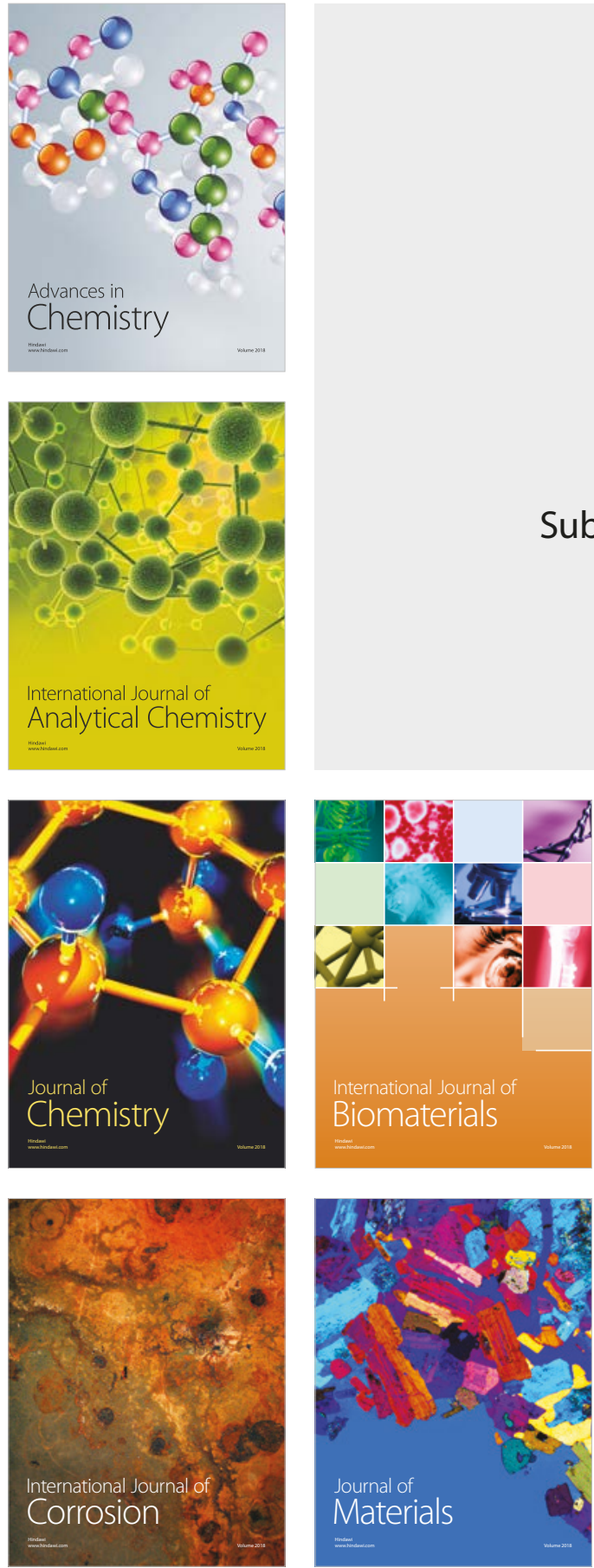

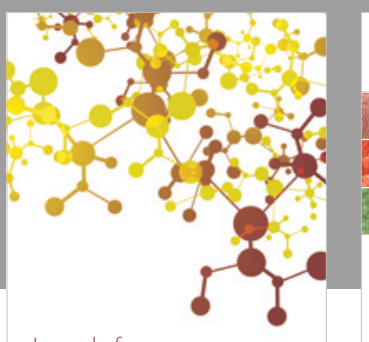

Journal of

Applied Chemistry
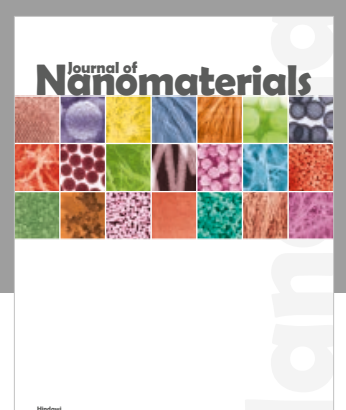

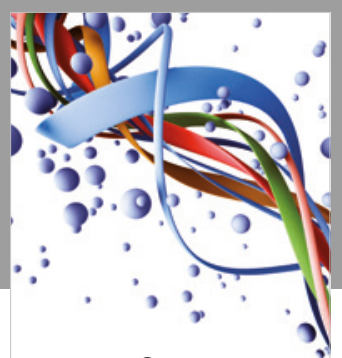

Scientifica

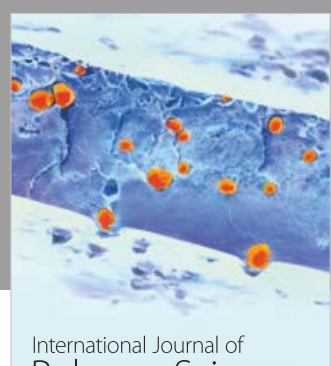

Polymer Science

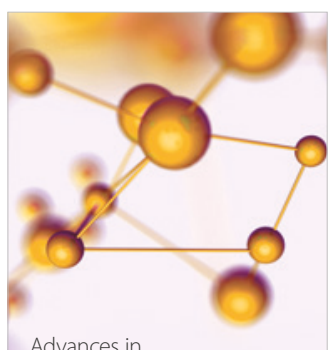

Physical Chemistry
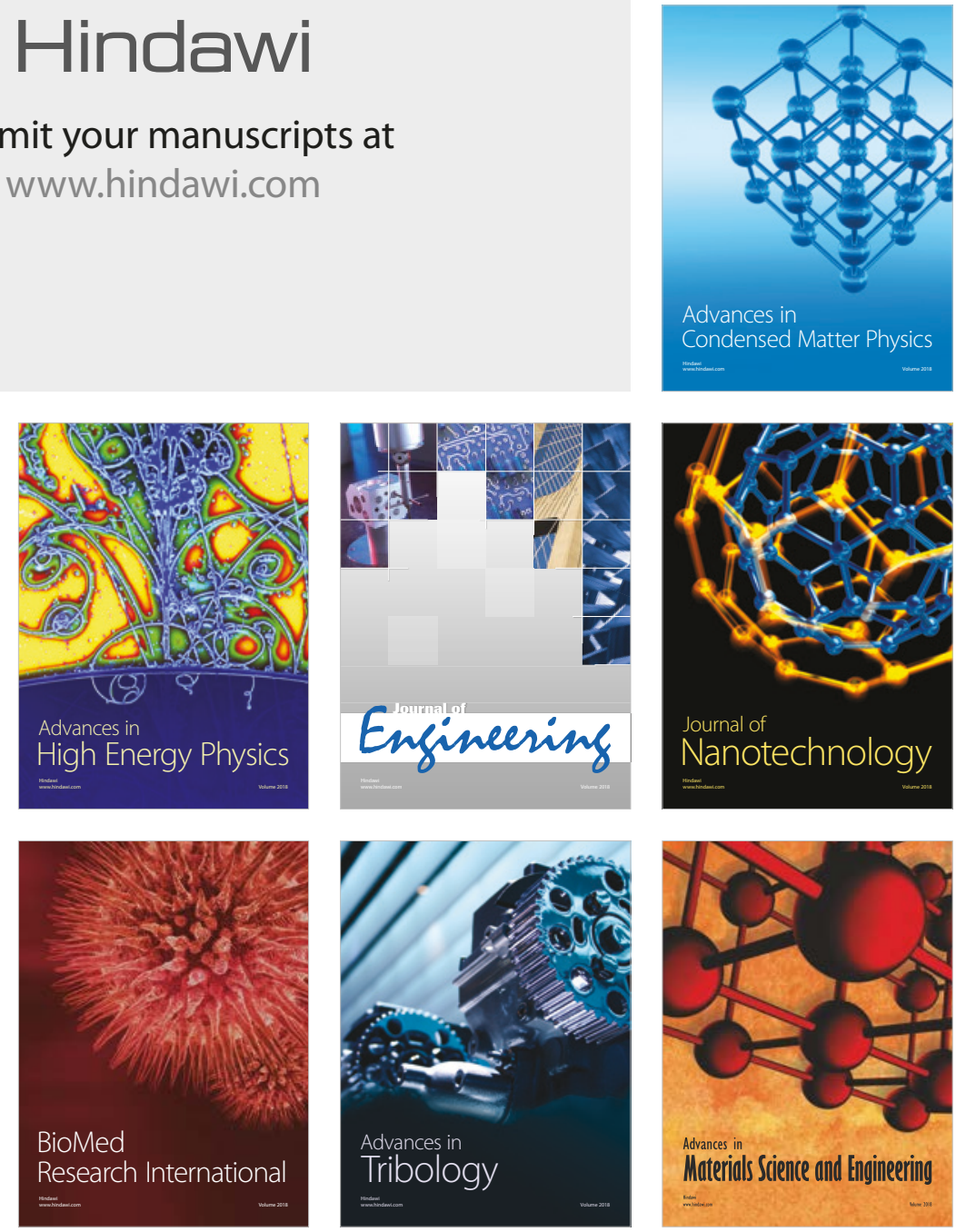